\title{
ASPS, 3.
}

Bonifacio VIII papa, avendo ricevuto una supplica da parte della regina Maria d'Ungheria, dona a quest'ultima il monastero di S. Pietro a Castello di Napoli con i beni e i diritti connessi e con la facoltà di insediarvi un numero opportuno di monache per fondare un convento domenicano.

- (Source: A. Ambrosio, II monastero femminile domenicano dei SS. Pietro e Sebastiano di Napoli. Regesti dei documenti dei secoli XIV-XV, Salerno 2003, p. 3, reg. 1) -

1301 febbraio 25

Archive: BSNSP, 9CCV2

Facs. monasterium.net: http://monasterium.net/mom/AVSPS/ASPS_3/charter

BONIFATIUS episcopus, servus servorum Dei, carissime in Christo filie Marie, regine Sicilie illustri, salutem et apostolicam benedictionem. Affluentis devotionis affectus quo erga romanam | ecclesiam matrem tuam pollere dinosceris, promeretur, ut personam tuam, multis utique virtutum titulis insignitam, favoribus prosequentes uberibus votis tuis in hiis potissime liberaliter annuamus et per | que divine maiestatis conspectui reddaris acceptior, gratiosior habearis tibique preter laudis humane preconium salutis cumulus producatur. Habet siquidem exposite nobis tue petitionis | assertio quod inter cetera desideria mentis tue illud pregrande fore conspicitur, ut sacer fratrum Predicatorum ordo in orto plantatus ecclesie ad laudem et gloriam summi regis per tue | sollicitudinis studium tuique ministerii solertiam curiosam prosperis successibus gaudeat, letis fecundetur eventibus et votivis proficiat incrementis. Quare supplici postulabas instan|tia, ut in monasterio Sancti Petri ad Castellum de Neapoli ordinis Sancti Benedicti moniales sive sorores eiusdem Predicatorum ordinis ponere ac instituere libere | valeas, ut in illo ipse ac ille que in ipso monasterio eis successerint perpetuis futuris temporibus permaneant, benignam tibi licentiam concedere dignaremur. Nos itaque huiusmodi tuum | laudabile desiderium salubreque propositum dignis in domino laudibus attollentes et volentes patris more benivoli, ut illud de apostolice sedis liberalitate munifica efficaciter impleatur. Gerentes | quoque circa prefatum Predicatorum ordinem specialis dilectionis affectum tibi prelibatum monasterium Sancti Petri cum domibus, officinis, viribus et pertinentiis suis omnibus ubilibet | constitutis necnon thesauro, reliquiis et ecclesiasticis ornamentis auctoritate apostolica de gratia speciali concedimus et donamus tibique ponendi ac instituendi libere in eodem | moniales sive sorores ipsius Predicatorum ordinis, usque ad numerum de quo tua viderit expedire discretio, ut per eas necnon et illas que ipsis in eodem monasterio successerint ibidem perpetuo sub | ipsius ordinis observantia virtutum domino serviatur plenam et liberam auctoritate predicta licentiam elargimur. Ut autem moniales sive sorores predicte, que in eodem mona|sterio pro tempore fuerint, in suis actibus salubrius et honestius dirigantur, auctoritate memorata statuimus et etiam ordinamusa ut in monasterio ipso priorissa continue | habeatur a monialibus ipsisb sive sororibus communiter eligenda. Quodque predictum monasterium omnibus et singulis privilegiis, indulgentiis, gratiis et concessionibus gaudeat, | que [I]ocis aliis e[iusde]m Predicatorum ordinis a sede apostolica su[nt] [co]ncessa. Nulli ergo omnimo hominum I[icea]t hanc paginam nostre concessionis, donazioni[s] statuti et ordinatio|nis infringere vel ei ausu temerario contrarre. Siquis autem 
hoc attemptare presumpserit indignationem omnipotentis Dei et beatorum Petri et Pauli, apostolorum eius, se noverit | incursurum. Datum Laterani .V kalendis martii, pontificatus nostri anno septimo. (BD). 